\title{
Inclusão escolar: concepções de psicólogos escolares e educacionais
}

\author{
Thaisa da Silva Fonseca* \\ Camila Siqueira Cronemberger Freitas** \\ Fauston Negreiros ${ }^{* * *}$
}

\section{Resumo}

Este estudo teve como objetivo investigar a concepção de psicólogos escolares e educacionais sobre a inclusão escolar. Tratou-se de um estudo de campo, qualitativo, descritivo, que teve como participantes dez psicólogos escolares e educacionais que atuavam na Educação Básica em escolas da rede privada de ensino. O instrumento de coleta de dados utilizado foi um roteiro de entrevista semiestruturada, analisado pelo método da análise de conteúdo. Mediante a análise, obtiveram-se cinco categorias: inclusão escolar como relevante e desafiadora; inclusão escolar como obrigatoriedade legal; promoção da inclusão escolar; escola como espaço de aprendizagem e/ou socialização; e benefícios da inclusão escolar. Os resultados apontaram que os psicólogos escolares e educacionais concebem a inclusão escolar como um processo relevante, desafiador e benéfico para os envolvidos. Os desafios abrangeram aspectos relacionados principalmente à necessidade de suporte físico, humano e governamental para a efetivação da inclusão escolar. Os benefícios direcionaram-se para todos os alunos e para os profissionais que atuam no ambiente escolar.

Palavras-chave: Educação inclusiva; Educação Especial; Psicologia da Educação.

\footnotetext{
* Mestranda em Psicologia pela Universidade Federal do Piauí (UFPI), Parnaíba, Piauí, Brasil.

** Mestre em Educação pela Universidade Federal do Piauí (UFPI), Teresina, Piauí, Brasil.

*** Doutor em Educação pela Universidade Federal do Ceará (UFC), Parnaíba, Piauí, Brasil.
} 


\section{School inclusion: educational and shool psychologists conceptions}

\section{Abstract}

This study aimed to investigated the educational and school psychologist conception about school inclusion. The study was accomplished in a qualitative and descriptive field in which participated ten educational and school psychologists who worked in Basic Education in private schools. The data collected were made through a semi-structured schedule interview. They were analyzed from the content analysis method. Through the analysis, five categories were obtained: school inclusion as relevant and challenging; school inclusion as legal obligation; promotion of school inclusion; school as a space for learning and / or socialization; and benefits of school inclusion. The results have showed that educational and school psychologists watch the school inclusion as beneficial, challenging and relevant process for all those involved on it. The challenges approach aspects mainly related to necessity of a governmental human and pshysical support for and effective school. All those involved in the school ambit, studentes and profissionals earned benefits.

Keywords: Inclusive Education; Special Education; Educational Psychology.

\section{Inclusion scolaire: conception de psychologues scolaires et pédagogiques}

\section{Résumé}

Cette étude visait à enquêter la conception de psychologues scolaires et pédagogiques par rapport au sujet d'inclusion scolaire. Le projet consiste dans un travail de terrain, qualitatif, descriptif, auquel ont participé dix psychologues scolaires et pédagogiques qui travaillent dans l'éducation de base dans les écoles privées. L'instrument utilisé est un script d'entretien semi-structuré, analysé par le méthode de l'analyse de contenu. Grâce au diagnostic, cinq catégories ont été obtenues : l'inclusion scolaire comme pertinente et stimulante ; l'inclusion scolaire en tant qu'obligation légale ; la promotion de l'inclusion scolaire ; l'école comme espace d'apprentissage et / ou de socialisation ; et finalement les avantages de l'inclusion scolaire. Les résultats ont indiqué que les professionnels considèrent l'inclusion scolaire comme un processus pertinent, stimulant et bénéfique pour les personnes impliquées. Les défis couvraient aspects liés principalement à la nécessité d'un soutien physique, humain et gouvernemental pour la mise en ouvre de l'inclusion scolaire. Les avantages s'adressent à tous les étudiants et professionnels travaillant dans le milieu scolaire.

Rechercher: Éducation Inclusive; Éducation Spéciale; Psychologie de L'Éeducation. 


\section{Introdução}

A temática da inclusão escolar apresenta-se notória por se encontrar em processo de efetivação e por evidenciar um percurso de lutas para a garantia do acesso de todos os alunos ao currículo na classe comum da escola regular. Da Antiguidade à Contemporaneidade, nota-se um processo que vai desde o abandono, institucionalização e integração até a inclusão, a qual amplia o seu público-alvo e passa a abranger não somente as pessoas com deficiência como também, no campo escolar, as demais pessoas público-alvo da educação especial.

Os progressos na relação sociedade e deficiência permitiram conquistas no campo educacional, sendo quatro os momentos característicos desse processo: extermínio; segregação/institucionalização; integração; e inclusão. Os dois primeiros correspondem ao período pré-científico, no qual a dimensão espiritual era atribuída como explicação para os quadros médicos e psicológicos que diferissem do que era postulado como normalidade. A partir do século XIX, no período científico, identificam-se os outros dois momentos que sintetizam marcos na defesa e promoção de direitos humanos (FERNANDES, 2013). A inclusão é caracterizada como:

[...] uma proposta da aplicação prática ao campo da educação de um movimento mundial, denominado inclusão social, que implicaria a construçáo de um processo bilateral no qual as pessoas excluídas e a sociedade buscam, em parceria, efetivar a equiparação de oportunidades para todos, construindo uma sociedade democrática na qual todos conquistariam sua cidadania, na qual a diversidade seria respeitada e haveria aceitação e reconhecimento político das diferenças (MENDES, 2006, p. 395).

O contexto político brasileiro é favorável para a inclusão, no entanto, dispositivos legais são insuficientes para garantir a escolarização bem-sucedida, uma vez que isso requer mudanças atitudinais e melhor norteamento quanto ao desenvolvimento de novas práticas (SILVA, 2010). Considera-se relevante que a escola desenvolva práticas que contribuam para a efetivação da inclusão, devendo adaptar-se, juntamente com a sociedade, para receber a todos. (MENDES; RODRIGUES; CAPELLINI, 2003). Para que todos aprendam, interajam e tenham igualdade de oportunidades no ambiente escolar, mudanças estruturais envolvendo a remoção de barreiras físicas e a organização de suportes humanos e instrumentais são fundamentais (FERNANDES, 2013).

Em pesquisa sobre a inclusão no município de Araras, São Paulo, corroborouse que a inclusão bem sucedida envolve a cooperação dos membros da comunidade escolar, o que implica em apoio mútuo, compartilhamento das responsabilidades referentes ao processo educativo dos alunos público-alvo da educação especial e promoção de um ambiente que estimule habilidades de resolução de problemas. Profissionais comprometidos e com formação profissional que contemplou conteúdos relacionados à educação inclusiva contribuem para que os desafios encontrados no dia a dia possam ser superados (LUCCA, BAZON, LOZANO, 2015). O processo de inclusão pressupóe ação receptiva e acolhedora da sociedade não somente para pessoas com deficiência como também para outras minorias. Aliada aos direitos à apren- 
dizagem e à participação de todos, a diversidade é enfatizada nas escolas. $\mathrm{O}$ "especial" da educação não se centra em um local e perfil de aluno, recebendo o significado de conjunto de recursos e serviços postos a serviço da educação para oferecer respostas educativas aos alunos em seu processo de aprendizagem (FERNANDES, 2013).

A inclusão amplia o público-alvo da educação especial, antes restrito às pessoas com deficiência, e promove importantes discussões sobre como a sociedade pode melhor organizar-se para oferecer um processo de ensino-aprendizagem que atenda às necessidades de todos os alunos. As escolas inclusivas têm como foco a flexibilidade curricular e metodológica visando à aceitaçáo das diferenças dos alunos. A ênfase é transferida das diferenças individuais para as condiçôes de ensino-aprendizagem oferecidas pela escola (MAGALHÃES, CARDOSO, 2011). Destarte, a inclusão é abordada como compromisso ético de acompanhamento do processo de aprendizagem de todos os alunos, considerando um "equívoco pensar em escolas como espaços de socialização ou do exercício de sentimento e solidariedade, apenas" (CARVALHO, 2008, p.48).

No entanto, a educação de alunos que são inclusos ou não como público-alvo da educação especial devem possuir os mesmos significados e sentidos. Para ambos, os espaços de interação são relevantes para promoção do conhecimento escolar e do desenvolvimento pessoal (FERREIRA, FERREIRA, 2013). A escola deve atentar-se, assim, para os conhecimentos escolares, para a sociabilidade e para a formação de indivíduos sensíveis à diversidade (GÓES, 2013).

Além dos benefícios de aprendizagem, socialização e formação pessoal, o processo inclusivo beneficia a todos os alunos. Ao ajudar aqueles que necessitam, os demais alunos da classe regular aprendem no exercício de cidadania, por exemplo. Além da aprendizagem, o investimento na independência e autonomia da pessoa com deficiência também deve ser enfatizado nas escolas (MENDES, RODRIGUES, CAPELLINI, 2003).

A inclusão envolve diversos desafios, tais como a organização e os valores da sociedade, as prioridades definidas pelas políticas públicas, a formação docente, a infraestrutura, os problemas vinculados às diferentes condiçóes que afetam o desempenho acadêmico e a formaçáo pessoal de sujeitos público-alvo da educação especial (GÓES, LAPLANE, 2013). Os desafios desse processo não se restringem ao espaço escolar, englobando desde aspectos da sociedade e do governo até aspectos estruturais da escola e atitudinais de seus membros, que, muitas vezes, não focalizam na formulaçáo de estratégias para promoçáo da aprendizagem desses alunos. O caráter obrigatório da inclusão não subsidia, muitas vezes, as escolas com condições físicas, organizacionais, pedagógicas e profissionais necessárias a uma educação para a satisfação das diferentes necessidades educacionais dos alunos. Com a obrigatoriedade da matrícula imposta pelas políticas e legislaçóes, muitas vezes o aluno é inserido junto aos demais, no entanto, a escola não desenvolve açóes para suas necessidades de aprendizagem. Nessa perspectiva, o direito do aluno é efetivado legalmente, entretanto, na prática é cumprido parcialmente, uma vez que lhe é garantido o direito de estudar, mas não 
lhe é fornecida garantia de permanência com aprendizagem mediante a elaboração de alternativas pedagógicas adequadas à sua singularidade e situaçáo de ensino e aprendizagem (SANTOS, 2011).

Os professores são considerados atores educacionais relevantes no processo inclusivo. Em estudo sobre a inclusão escolar sob a ótica de professores da escola básica, percebeu-se tanto homogeneidade na forma de ver esses alunos como sujeitos que têm as marcas da diferença, como heterogeneidade nos espaços formativos, por meio da experiência, da academia e da formação em serviço. No entanto, essas práticas formativas são consideradas como superficiais diante das demandas dos professores (ZUCCHETTI, 2011). Oferecer oportunidades iguais de educação náo significa dispensar o mesmo tratamento, ou seja, a escola deve oferecer o mesmo acesso para todos, mas os meios utilizados serão diferentes (KASSAR, 2013).

O processo de inclusão escolar enfatizou a relevância da promoção de condiçôes de um processo de ensino-aprendizagem que beneficie a todos os alunos. Diante desse cenário, o psicólogo escolar e educacional passou a atuar em demandas oriundas $\mathrm{da}$ inclusão e em projetos que focalizem esse novo contexto. Essa pesquisa objetivou investigar a concepção de psicólogos escolares e educacionais sobre a inclusão escolar.

\section{Metodologia}

Essa pesquisa é classificada como qualitativa do tipo descritiva.

\section{Participantes}

Participaram da pesquisa dez psicólogas escolares e educacionais, sexo feminino, de 25 a 35 anos de idade, que atuavam na Educação Básica, em escolas privadas do município de piauinense. A maioria concluiu o curso de graduação em instituiçóes de ensino privadas e todas possuíam Pós-graduação Latu Sensu em andamento ou concluídas.

\section{Local da Pesquisa}

$\mathrm{O}$ local da pesquisa foram escolas regulares privadas do município de $\mathrm{X}$ (omissão para avaliação cega) em que os participantes atuavam como psicólogos escolares e educacionais na Educação Básica. O critério de escolha desse cenário de pesquisa foi a prevalência de psicólogos escolares e educacionais atuando na rede privada em comparação à rede pública de ensino no municipío.

\section{Instrumento de Coleta de Dados}

Roteiro de entrevista semiestruturada: continha perguntas abertas sobre identificação, formação profissional e concepções sobre a inclusão escolar.

\section{Coleta de Dados}

A pesquisa obedecia às regulamentaçóes da Resoluçáo 466/12 do Conselho Nacional de Saúde/Ministério da Saúde e obteve aprovação do Comitê de Ética em Pesquisa (CEP), com parecer de aprovaçáo no 1.334 .025 . Os participantes consentiram a sua participaçáo através do Termo de Consentimento Livre e Esclarecido (TCLE), documento composto por duas vias e que informa sobre a pesquisa. 


\title{
Análise de Dados
}

O método de análise de dados utilizado foi a análise de conteúdo, definido como um conjunto de técnicas de análise das comunicaçóes que objetiva obter através de procedimentos sistemáticos de descrição do conteúdo indicadores que possibilitem a inferência de conhecimentos dessas mensagens (BARDIN, 2011).

\section{Resultados e discussão}

Os resultados permitiram a obtenção de cinco categorias de análise em torno das concepçóes das psicólogas escolares e educacionais sobre a inclusão escolar: inclusão escolar como relevante e desafiadora; inclusão escolar como obrigatoriedade legal; promoção da inclusão escolar; escola como espaço de aprendizagem e/ou socialização; e benefícios da inclusão escolar.

\section{Inclusão escolar como relevante e desafiadora}

Todas as psicólogas escolares e educacionais consideraram a inclusão escolar como relevante, no entanto, ainda ocorrendo lentamente e com desafios para ser efetivada conforme estabelecido pelas legislaçôes. Essa concepção pode ser exemplificada nas seguintes falas:

\begin{abstract}
A inclusão já deveria ter acontecido há muito tempo, ainda se está aprendendo [...] eu percebo como desafio, pra família e pra escola, pra família de todo o luto em relação ao laudo, a correria atrás de profissionais, de fazer com que as pessoas entendam as especificidades do filho, e da escola de saber lidar com a família e de se preparar pra trabalhar com o aluno né [...] é muito difícil fazer a inclusão acontecer como diz no papel. PEE3
\end{abstract}

A proposta é muito interessante [...] claro que se nós considerarmos o que era inclusáo há dez, vinte anos, o que havia na verdade era uma segregação, e se considerarmos o que é inclusão hoje a gente vê uma evoluçáo positiva, mas inclusão não se restringe a oferecer recursos especializados, é todo um contexto [...] ainda é a passos lentos, nós do [...] somos uma escola eminentemente inclusiva e pensar em educação inclusiva hoje é pensar em desafio e não em desafio que não possa ser superado, mas desafio puxa estratégia e estratégia puxa mudança de postura que puxa formação, são variáveis em relação a um ponto só né. PEE6

[...] eu acho que tá engatinhando e em alguns casos tá mais pra integração do que pra inclusão, existem as iniciativas, os recursos, mas a inclusão em si talvez ainda náo aconteça como deveria ser, mas acredito que o caminho seja esse mesmo, pelo menos a gente já deu esse primeiro passo. PEE7

A inclusão escolar envolve desafios, como a organização e os valores da sociedade, as prioridades definidas pelas políticas públicas, a infraestrutura, os problemas relacionados às condiçóes que afetam o desempenho acadêmico e a formação pessoal do sujeito (GÓES, LAPLANE, 2013; MACHADO, OLIVEIRA, 2017; MIETO, BARBATO, ROSA, 2017). Esses desafios do processo inclusivo foram verificados nos relatos das participantes da pesquisa, como: a dificuldade do aluno que estuda na sala 
comum acompanhar o conteúdo; a falta de implicação governamental no processo inclusivo; a necessidade de reorganização da dinâmica familiar mediante o diagnóstico; a necessidade de reestruturação da escola para atender às demandas; a mudança do corpo docente concomitante à mudança de série; a inclusão ainda não ser efetiva como a legislação sugere; a existência de escolas que ainda dificultam o acesso de pessoas público-alvo da educação especial; e, por fim, a dificuldade inicial no processo de inclusão. Contudo, PEE6 sugere que o desafio da inclusão escolar pode ser superado por meio da criaçáo de estratégias, como a formação continuada e da mudança atitudinal. Essa participante implicou-se, de maneira direta, na superaçáo das dificuldades do processo inclusivo. Além das falas sugerirem o caráter processual da inclusão, PEE6 e PEE7 mencionaram o seu aspecto histórico ao se referirem à segregação e à integração, momentos históricos característicos da relação da sociedade com a pessoa com deficiência (FERNANDES, 2013).

O aumento do número de alunos público-alvo da educação especial no ensino regular demonstrou as limitaçôes do sistema educacional (SANTOS, 2011). A grande quantidade desses alunos nas salas de aula também foi ressaltada por quatro psicólogas escolares e educacionais, como observadas nas falas a seguir:

\begin{abstract}
[...] numa turma de trinta e cinco alunos [...] existem duas, três, quatro, cinco com especificidades. PEE6

[...] a dificuldade é que nós temos que ter mais escolas inclusivas, entáo o fato de sobrecarga de crianças especiais dentro da escola, por exemplo, eu tenho turmas que hoje tem três crianças especiais, entáo é uma sobrecarga dentro da escola [...] porque outras escolas não recebem né. PEE8
\end{abstract}

PEE8 explicitou a ausência de uma maior quantidade de escolas inclusivas. No entanto, esse aumento na demanda pode estar associado ao maior acesso de crianças público-alvo da educaçáo especial ao ambiente escolar, uma vez que psicólogas escolares e educacionais de outras escolas que foram locais da pesquisa também mencionaram esse dado.

\title{
Inclusão escolar como obrigatoriedade legal
}

Nos relatos das participantes da pesquisa também foi possível verificar referência à obrigatoriedade legal da inclusão escolar, a qual facilitou o acesso, mas não garantiu a efetividade dessa inclusão:

\footnotetext{
[...] precisamos de adaptaçóes físicas e pedagógicas pra essas crianças e não é fácil, a escola acaba ficando exposta nessa situação, porque ela não tem escolha, tem que fazer, e eu acho que se tivesse sido feito de outra forma teriam melhores resultados, hoje em dia a inclusão na escola regular acontece ainda muito pra dizer né, pela obrigaçáo da lei, e no caso a criança acaba não sendo inclusa, acaba estando guardada lá [...]. PEE3

[...] infelizmente o caminho foi esse, teve que se tornar algo obrigatório pra que as instituições e as pessoas levassem isso em consideração né [...]. PEE7
} 
O caráter obrigatório da inclusão não subsidia as escolas com condições físicas, organizacionais, pedagógicas e profissionais necessárias a uma educaçâo para a satisfação das diferentes necessidades educacionais. É garantido ao aluno o direito de estudar, mas não lhe é garantida permanência com aprendizagem (SANTOS, 2011). Os dispositivos legais são insuficientes para a garantia de uma escolarização bem-sucedida, embora o contexto brasileiro seja favorável à inclusão (MACHADO; ALBUQUERQUE, 2017; SILVA, 2010).

\section{Promoção da inclusão escolar}

Algumas psicólogas escolares e educacionais trouxeram a perspectiva de reestruturaçáo da escola para a promoçáo da inclusão escolar. Essa concepção, exemplificada a seguir, se coaduna à visão atual discutida pela literatura de que é a escola que deve criar condiçóes para que a inclusão ocorra, ou seja, é a escola que deve se adaptar para promover a aprendizagem dos alunos público-alvo da educaçáo especial e não o contrário:

[...] os recursos vão desde recursos materiais, pessoais, de treinamento de professores, contratação de profissionais, acompanhantes, essa reestruturaçáo ela vai acontecer, vai ter que partir mesmo da escola né. PEE3

[...] os profissionais que atuavam aqui já sentiam necessidade de se capacitar ou de olhar para essa criança de uma forma diferente, pra que ela estivesse incluída [...] e a gente tenta com essas formaçôes continuadas, com essa capacitação, com palestra, com a prática de sala de aula porque aqui nós temos basicamente um psicólogo por segmento né. PEE9

Essa transformação do ambiente escolar pode ocorrer tanto por meio de mudanças estruturais e da organização de suportes humanos e instrumentais (FERNANDES, 2013) como por meio da flexibilidade curricular e metodológica, transferindo a ênfase das diferenças individuais para as condiçóes de ensino-aprendizagem, atentando para as particularidades dos alunos (MAGALHÃES, CARDOSO, 2011; JANUZZI, 2017). As mudanças atitudinais e o desenvolvimento de novas práticas são fundamentais para a escolarização bem sucedida (SILVA, 2010).

As participantes também revelaram uma percepção de promoção da inclusão que abrange toda a comunidade escolar e que focaliza no trabalho em equipe, como a seguir:

[...] a inclusão não se restringe só ao psicólogo, só ao psicopedagogo ou só ao professor, a inclusão abrange toda a escola, desde os serviços mais simples até a direção da escola [...]. PEE6

[...] então a gente vê o resultado da inclusão, é muito trabalhoso no início, porque você lida com a família, com a própria criança, com o sistema de ensino, com os profissionais da escola, não é só o professor que tem contato com essa criança, é o pessoal da cantina, da limpeza, o porteiro, o atendente, todo mundo da escola tem e precisa ser capacitado pra estar com essas crianças [...]. PEE9 
PEE6 e PEE9 apontaram um dado importante de que a inclusão deve ser um paradigma que envolva toda a escola, não se restringindo apenas à equipe pedagógica e de gestáo escolar, mas incluindo os diversos profissionais que atuam no dia a dia das escolas ou que a ela esteja relacionada. Lucca, Bazon e Lozano (2015) também obtiveram como resultados de sua pesquisa que a inclusão envolve a colaboração dos envolvidos no processo e implica em apoio mútuo, compartilhamento de responsabilidades e criação de um ambiente estimulador de habilidades de resolução de problemas.

O professor, profissional que lida com os alunos no dia a dia em sala de aula, foi apontado como ator relevante no processo escolar e inclusivo. PEE5 e PEE6 apontaram a carga-horária elevada e a grande quantidade de alunos, inclusos ou não como público-alvo da educaçáo especial, em sala de aula como desafios para o professor:

[...] é um desafio grande por conta da carga-horária dos professores, que precisa de planejamento, de momento de correção, de avaliação, então é o tempo todo trabalhando [...]. PEE5

[...] o grande desafio é esse, dentro dessa coletividade que é a escola trabalhar essa especificidade, esse é o grande desafio de quem faz a escola hoje, principalmente do professor que é a linha de frente com o aluno né e porque que muitas vezes nós estamos ainda em passos lentos [...] porque é muito difícil realmente fazer isso numa turma, por exemplo, de trinta e cinco alunos [...] e dentro desses trinta e cinco existem dois, três, quatro, cinco com especificidades, é como se o professor tivesse que ser vários em um só né, e nós sabemos que existem professores que conseguem dar conta muito bem dessas demandas, existem outros que a gente ainda precisa tá fazendo algumas orientaçóes, tá dando alguns direcionamentos [...]. PEE6

Profissionais comprometidos e com formação adequada às necessidades dos alunos no ensino regular, contribuindo para que as falhas e dificuldades enfrentadas no dia a dia possam ser superadas são de fundamental importância (LUCCA, BAZON, LOZANO, 2015). As práticas formativas são consideradas superficiais diante das demandas dos professores (ZUCCHETTI, 2011). Com base nessa perspectiva, algumas participantes apontaram a formação como aspecto facilitador do processo inclusivo, conforme visto nas falas a seguir:

[...] dos próprios professores, a gente faz até algumas formações, mas eles têm dificuldade de compreender que eles precisam de atençáo maior, às vezes a gente precisa fazer uma prova diferenciada e aí os professores não entendem bem como é essa diferenciação [...]. PEE1

[...] vem a formação do professor, seja no curso de Pedagogia que é mais amplo, seja nos cursos mais específicos, isso também tem que vir da própria formação porque a gente tem disciplinas na Psicologia que contempla a educaçáo inclusiva, mas a teoria muitas vezes é divergente da prática, porque a gente náo pode querer que o aluno que tem alguma especificidade se encaixe naquelas características dos demais, só que a gente também não pode excluir ele de 
tudo porque ele faz parte desse coletivo, então ainda é muito lento e ainda é delicado porque a gente tem que mexer também com a formação e ai vem a formação do professor, do psicólogo que tá na escola, do coordenador pedagógico, vem a formaçáo, por exemplo, do porteiro ao receber esse aluno, então é um processo que não restringe só a quem lida diretamente com o aluno, mas quem lida, quem faz a escola como um todo [...]. PEE6

PEE6 refletiu um ponto importante, que é dessa formação não se restringir somente ao professor, mas também envolver toda a comunidade escolar com seus diversos profissionais. É nesse sentido que profissionais, como os psicólogos escolares e educacionais, passam a atuar não somente como facilitador de processos formativos, mas também como beneficiários. No entanto, as pesquisas da área educacional ainda não abordam a formaçáo dos demais profissionais da comunidade escolar, como recepcionistas, secretárias, etc. (CARVALHO et al., 2017)

\section{Escola como ambiente de aprendizagem e/ou socialização}

Outro aspecto relevante verbalizado por algumas participantes foi referente à escola como espaço de aprendizagem, conforme expresso a seguir:

[...] num mundo em que vivemos se faz necessário que a gente possa dar o melhor dessa educação também pra essas crianças e adolescentes [...]. PEE4

[...] dentro de um currículo comum a criança tem um currículo adaptativo. PEE8

A ênfase na aprendizagem é retratada pela literatura ao considerar a inclusão como compromisso ético do processo de aprendizagem de todos os alunos (CARVALHO, 2008; PLETSCH, SOUZA, ORLEANS, 2017). Outras psicólogas escolares e educacionais referiram-se a escola como ambiente de socialização:

[...] ela faz com que essa criança veja outras formas de se conviver e ela aprenda outras formas né de se socializar [...]. PEE5

[...] a criança com necessidade especial ela precisa se socializar com os demais né [...]. PEE7

[...] é um suporte a mais para que consiga interagir com os outros né [...]. PEE9

Alguns autores (GÓES, 2013; RODRIGUES, 2017) são adeptos de uma visão holística desse processo e afirmam que a escola deve atentar-se para os conhecimentos escolares, para a sociabilidade e para a formaçáo dos indivíduos. Nessa perspectiva, PEE1, PEE2 e PEE3 mencionaram a importância do ambiente da escola regular tanto para a aprendizagem como para a socializaçáo:

[...] estuda na escola regular, na sala regular, mas não acompanha [...] ele não pode tá só no meio daqueles que tem dificuldade de aprendizagem ou que tem deficiência, ele precisa tá nesse meio porque na sociedade ele vai conviver com pessoas que não têm dificuldade, deficiência [...]. PEE1 
[...] se precisa de adaptação isso é feito [...] se a gente vai conseguir garantir a aprendizagem dessa criança [...] a inclusão melhora sim a criança, possibilita a ela uma oportunidade social melhor, que elas ficavam muito marginalizadas da sociedade mesmo, às margens, e hoje a gente vê o progresso dessas crianças [...]. PEE2

[...] a escola acima de tudo ela precisa ser um espaço de aprendizagem, então fazer com que esse aluno aprenda vai ser o maior desafio e pra isso precisa ter claro qual o seu papel nisso e ir atrás de recursos pra isso [...] eu acho que a escola precisa desse suporte que aí a gente diz que uma coisa tem que acontecer sendo que o modelo de escola ainda é um modelo muito tradicional né, assim de entendimento, ela ainda é muito difícil acontecer para crianças ditas normais né que ai você precisa entender cada ser humano como único, mesmo as crianças neurotípicas nenhuma aprende de um mesmo jeito, todas aprendem de um jeito diferente [...] pras crianças especiais é importante estarem em um ambiente onde tem outras crianças, que são as neurotípicas que a gente chama [...]. PEE3

Nesse sentido, a educação de alunos inclusos ou não como público-alvo da educação especial deve possuir os mesmos significados e sentidos, ou seja, para ambos os espaços de interação são relevantes para a promoção do conhecimento escolar e para o desenvolvimento pessoal (FERREIRA, FERREIRA, 2013; RODRIGUES, 2017). PEE3 também expressou, conforme observado anteriormente, sobre o modelo tradicional de escola e refletiu a aprendizagem como sendo única em cada indivíduo, o que se relaciona ao apontado pela literatura de que oferecer oportunidades iguais de educação não implica dispensar o mesmo tratamento, ou seja, a escola deve oferecer o mesmo acesso para todos os alunos, contudo, os meios utilizados serão diferentes (KASSAR, 2013).

\section{Benefícios da inclusão escolar}

A inclusão escolar foi apontada como benéfica por todas participantes. PEE3 ressaltou o benefício da inclusão para os profissionais que atuam na escola regular, uma vez que esse processo oportuniza crescimento pessoal e profissional:

[...] então assim fazer inclusão realmente na escola regular ainda é muito difícil, mas eu acho que é possível e ter essas crianças na escola elas lhes dão a oportunidade de você crescer né, pessoalmente, profissionalmente, de você pesquisar, estudar, encontrar formas de chegar até elas. PEE3

Outras participantes apontaram a inclusão escolar como benéfica para todos os alunos, o que pode ser visto por meio das falas abaixo:

[...] a gente vê a evolução dessas crianças que estão na escola regular [...] a gente acompanha crianças que tem na turma um aluno com deficiência que já estão juntos há quatro, cinco anos e você vê o comportamento dessas crianças diante deles é totalmente diferente, é comportamento de ajuda, de auxílio, de compreender e de entender que muitos adultos náo têm, eles conseguem ter isso com naturalidade, por já conviver a tanto tempo, a conhecer as necessidades de cada um. PEE5 


\begin{abstract}
Você vê resultado das outras crianças ditas "típicas" e das crianças que tem algum tipo de diagnóstico, vê a evolução dos dois lados [...] eu vejo como muito positiva a inclusão porque as crianças avançam muito, é um ambiente que traz ganhos pra elas. PEE9
\end{abstract}

A ampliação dos benefícios da inclusão para os alunos que não são público-alvo da educação especial é aspecto ressaltado nos estudos. Os demais alunos, ao ajudar aqueles que necessitam, aprendem no exercício de cidadania. Além da aprendizagem, a independência e autonomia da pessoa com deficiência também deve ser enfatizada nas escolas (DIAS ET AL., 2016; MENDES, RODRIGUES, CAPELLINI, 2003; RODRIGUES, 2017). A fala de PEE5 evidenciou a convivência, ainda enquanto criança, com pessoas público-alvo da educação especial como benéfica em relação à sensibilidade e à diversidade enquanto adulto. Nessa perspectiva, estudos apontam que a inclusão também contribui para a formação de indivíduos sensíveis à diversidade (GOÉS, 2013).

\title{
Considerações finais
}

A inclusão escolar demanda mudanças de caráter social e envolve a reflexão sobre o sistema educacional e a redefinição de estratégias que se coadunam ao novo contexto que emerge e que fazem parte da prática cotidiana de seus profissionais, envolvendo toda a comunidade escolar.

Essa pesquisa objetivou investigar a concepção de psicólogos escolares e educacionais sobre a inclusão escolar. Acredita-se que o referido objetivo foi alcançado, sendo possível verificar a inclusão escolar como um processo relevante, desafiador e benéfico para os envolvidos. Os desafios abrangeram aspectos relacionados principalmente à necessidade de suporte físico, humano e governamental para a efetivaçáo da inclusão escolar. Os benefícios direcionaram-se não apenas para as pessoas público-alvo da educação especial, como também para os demais alunos e para os profissionais que atuam no contexto educacional.

A inclusão foi mencionada como abrangendo toda a comunidade escolar e realizando-se um trabalho em várias frentes, a partir da perspectiva de reestruturaçáo do ambiente escolar para atender às demandas oriundas do processo inclusivo, principalmente a aprendizagem. O professor foi apontado como ator relevante do processo inclusivo e que se depara com desafios referentes principalmente à elevada carga-horária de trabalho e à quantidade de alunos em sala de aula. A formação de professores e de outros profissionais foi sugerida como aspecto facilitador da inclusão.

Os estudos em torno do objeto investigado não se esgotam com essa pesquisa. Para estudos futuros, sugerem-se instituiçôes de ensino públicas como locais de pesquisa, com o intuito de verificar se as especificidades desse cenário, como disponibilidade de recursos materiais e humanos, contribui para a mudança de concepçôes sobre a inclusão escolar. Também se propóe a ampliação de outros membros da comunidade escolar como participantes da pesquisa. 


\section{Referências}

BARDIN, Laurence. Análise de Conteúdo. São Paulo: Ediçôes 70, 2011.

BARROS, M. C. M. S.; BRITO, M. I. M. S.; GUEDES, J. T. Educação inclusiva: possibilidades e desafios. Encontro Internacional de Formação de Professores e Fórum Permanente de Inovaçáo Educacional, v. 10, n. 1, mês/mês, 2017.

CARVALHO, D. R.; CUBAS, J. M.; HACK, N. S.; SILVA, V. A.; SCATOLIN, S. Crianças e adolescentes com deficiência: revisão da literatura (2009-2015) frente à garantia de direitos. Revista Uniandrade, v. 18, n. 2, p. 74-85, mês/mês, 2017. Disponível em: Acesso em:

CARVALHO, Rosita Edler. Das políticas de educação especial às políticas de orientação inclusiva. In: Escola inclusiva: a reorganização do trabalho pedagógico. Porto Alegre: Mediação, 2008. Cap. 3, p. 41-52.

DIAS, Paulo; SOUZA, Juliana; GONÇALVES, Manuela; FLORES, Pedro; PÉREZ, Juliana Diáz. Atitudes dos pares sobre a inclusão: contributos da adaptaçâo de um instrumento. Psicologia, v. 30, n. 2, p. 95-106, dez., 2016. Disponível em: < http://www.scielo.mec.pt/scielo.php?script=sci_abstract\&pid=S0874-20492016000200008>. Acesso em: 10 out. 2017.

DINIZ, M. Inclusão de pessoas com deficiência e/ou necessidades específicas: avanços e desafios. Autêntica, 2017.

FERREIRA, Maria Cecília Carareto; FERREIRA, Júlio Romero. Sobre inclusão, políticas públicas e práticas pedagógicas. In: GÓES, Maria Cecília Rafael de; LAPLANE, Adriana Lia Friszman de. Políticas e práticas de educação inclusiva. Campinas: Autores Associados, 2013. Cap. 2, p. 21-46.

FERNANDES, Sueli. Fundamentos para educaçáo especial. Curitiba: InterSaberes, 2013.

GIL, Antonio Carlos. Como Elaborar Projetos de Pesquisa. 4. ed. São Paulo: Editora Atlas S.A, 2009.

GÓES, Maria Cecília Rafael de. Desafios da inclusão de alunos especiais: a escolarização do aprendiz e sua constituição como pessoa. In: GÓES, Maria Cecília Rafael de; LAPLANE, Adriana Lia Friszman de. Políticas e práticas de educaçáo inclusiva. Campinas: Autores Associados, 2013. Cap. 4, p. 65-84.

GÓES, Maria Cecília Rafael de; LAPLANE, Adriana Lia Friszman de. Apresentação. In: Políticas e práticas de educaçáo inclusiva. Campinas: Autores Associados, 2013. Apresentação, p. 01-04.

JANNUZZI, Gilberta de Martino. A educaçáo do deficiente no Brasil. Autores Associados, 2017.

KASSAR, Mônica de Carvalho Magalhães. Matrículas de crianças com necessidades educacionais especiais na rede de ensino regular: do que e de quem se fala? In: GÓES, Maria Cecília Rafael de; LAPLANE, Adriana Lia Friszman de. Políticas e práticas de educaçáo inclusiva. Campinas: Autores Associados, 2013. Cap. 3, p. 47-64.

LUCCA, Josiele Giovana de; BAZON, Fernanda Vilhena Mafra; LOZANO, Daniele. A inclusão escolar no município de Araras: condiçōes e perspectivas. Educação: Teoria e Prática, Rio Claro, v. 25, n. 49, p. 340-356, mai./ago. 2015. Disponível em: <http://www.periodicos.rc.biblioteca.unesp.br/index.php/educacao/article/ view/7747/6859 >. Acesso em: 21 abr. 2016.

MACHADO, Laêda Bezerra; ALBUQUERQUE, Ednea Rodrigues de. Inclusão de alunos com deficiência na escola pública: as representaçóes sociais de professoras. Revista Diálogo Educacional, v. 12, n. 37, p. 10851104, set./dez,, 2017. Disponível em: <http://www2.pucpr.br/reol/pb/index.php/dialogo?dd1=7431\&dd99=view\&dd98=pb> Acesso em: 10 out. 2017

MACHADO, Dalva Míssias; OLIVEIRA, Elisangela Sobreira de. Inclusão escolar: estratégia docente no processo de avaliação. Revista Farol, v. 2, n. 2, p. 81-97, set./, 2017. Disponível em: <http://www.revistafarol.com. br/index.php/farol/article/view/32>.Acesso em: 10 out. 2017.

MAGALHÃES, Rita de Cássia Barbosa Paiva. Contribuiçôes para o debate sobre a aprendizagem da pessoa com deficiência na escola. In: MAGALHÂES, Rita de Cássia Barbosa Paiva (Org.) Educação inclusiva: escolarização, política e formação docente. Brasília: Liber Livro, 2011. Cap. 5, p. 91-106.

MAGALHÃES, Rita de Cássia Barbosa Paiva; CARDOSO, Ana Paula Lima Barbosa. Educação especial e educação inclusiva: conceitos e políticas educacionais. In: MAGALHĀES, Rita de Cássia Barbosa Paiva (Org.) Educação inclusiva: escolarização, política e formação docente. Brasília: Liber Livro, 2011. Cap. 1, p.13-34.

MANZINI, Eduardo José. Uso da entrevista em dissertaçôes e teses produzidas em um programa de pós-graduação em educação. Revista Percurso, Maringá, v. 4, n. 2, p. 149-171, 2012. Disponível em: < http://periodicos. uem.br/ojs/index.php/Percurso/article/view/18577>. Acesso em: 27 jul. 2017.

Revista Educação Especial | v. $31 \mid$ n. 62 | p. 603-616 | jul/set. 2018

Santa Maria

Disponível em: <https://periodicos.ufsm.br/educacaoespecial> 
MARIN, Alda Junqueira; ZEPPONE, Rosimeire Maria Orlando. O trabalho docente e a inclusão escolas: impactos e mudanças em sala de aula. Olhar de Professor, Ponta Grossa, v. 15, n. 1, p. 145-155, 2012. Disponível em: < http://www.uepg.br/olhardeprofessor>. Acesso em: 21 abr. 2016.

MENDES, Enicéia Gonçalves. A radicalização do debate sobre inclusão escolar no Brasil. Revista Brasileira de Educaçáo, Rio de Janeiro, v. 11, n. 33, p. 387-559, set./dez. 2006. Disponível em: <http://www.scielo.br/scielo. php?pid=S1413-24782006000300002\&script=sci_abstract\&tlng=pt>. Acesso em: 17 out. 2015.

MENDES, Enicéia Gonçalves; RODRIGUES, Olga Maria Piazentin Rolim; CAPELLINI, Vera Lúcia Messias Fialho. O que a comunidade quer saber sobre educação inclusiva. Revista Brasileira de Educaçáo Especial, Marília, v. 9, n. 2, p. 181-194, jul./dez. 2003. Disponível em: < http://www.abpee.net/homepageabpee04_06/ artigos_em_pdf/revista9numero2pdf/5mendes_rodrigues_capellini.pdf $>$. Acesso em: 26 fev. 2016.

MIETO, Gabriela Sousa de Melo; BARBATO, Silviane; ROSA, Alberto. Professores em transição: produção de significados em atuação inicial na inclusão escolar. Psicologia: Teoria e Pesquisa, v. 32, n. 5, p. 1-10, 2017. Disponível em: < http://www.scielo.br/scielo.php?pid=S0102-37722016000500209\&script=sci_abstract\&tln$\mathrm{g}=\mathrm{pt}>$. Acesso em: 10 out. 2017.

PLETSCH, Márcia Denise; SOUZA, Flávia Faissal de; ORLEANS, Luis Fernado. A diferenciação e o desenho universal na aprendizagem como princípios para a inclusão escolar. Revista Educaçáo e Cultura Contemporânea, v. 14, n. 35, p. 264-281, 2017. Disponível em: < http://periodicos.estacio.br/index.php/reeduc/article/ viewArticle/3114>. Acesso em: 10 out. 2017.

RODRIGUES, Maria Marilê. As contribuiçôes de Vygotsky para o desenvolvimento das crianças com deficiência. Id on Line Revista de Psicologia, v. 10, n. 33, p. 320-228, jan., 2017. Disponível em: < https://idonline. emnuvens.com.br/id/article/view/657/926>. Acesso em: 10 out. 2017.

SANTOS, Geandra Cláudia Silva. O professor e a educação de alunos com desenvolvimento atípico: reflexões e pistas de açōes significativas. In: MAGALHÂES, Rita de Cássia Barbosa Paiva (Org.) Educaçáo inclusiva: escolarizaçâo, política e formação docente. Brasília: Liber Livro, 2011. Cap. 6, p.107-134.

SILVA, Aline Maira da. A filosofia da normalização e o movimento de integração escolar. In:. Educaçáo especial e inclusáo escolar: histórias e fundamentos. Curitiba: Ibpex, 2010. Cap. 2, p. 49-89.

SOUZA, F. S. A atuação do psicólogo no contexto escolar em uma perspectiva crítica. Colloquium Humanarum, v. 14, n. 1, p. 01-06, março, 2017.

ZUCCHETTI, Dinora Tereza. A inclusão escolar vista sob a ótica de professores da escola básica. Educaçáo em Revista, Belo Horizonte, v. 27, n. 02, p. 197-218, ago. 2011. Disponível: <http://www.scielo.br/scielo. php?script=sci_arttext\&pid=S0102-46982011000200010>. Acesso em: 24 mar. 2016.

\section{Correspondência}

Thaisa da Silva Fonseca - Universidade Federal do Piauí. Campus Ministro Reis Velloso. CEP: 64202-020. Parnaíba, Piauí, Brasil.

E-mail: thaisafonseca23@hotmail.com - camilasiqueirapsi@gmail.com - faustonnegreiros@ufpi.edu.br

Recebido em 13 de dezembro de 2018

Aprovado em 19 de março de 2018

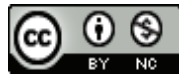

This work is licensed under a Creative Commons Attribution-NonCommercial 4.0 International (CC BY-NC 4.0) 